\title{
Simulation assisted process chain design for the manufacturing of bulk hybrid shafts with tailored properties
}

\author{
Timm Coors ${ }^{1}$ (i) - Florian Pape ${ }^{1}$ - Jens Kruse ${ }^{2}$. Thoms Blohm² Rüdiger Beermann $^{3}$ - Lorenz Quentin ${ }^{3}$. \\ Sebastian Herbst ${ }^{4}$. Jan Langner ${ }^{2} \cdot$ Malte Stonis $^{2} \cdot$ Markus Kästner $^{3}$. Eduard Reithmeier ${ }^{3}$. Florian Nürnberger ${ }^{4}$. \\ Gerhard Poll ${ }^{1}$
}

Received: 6 February 2020 / Accepted: 21 May 2020 / Published online: 9 June 2020

(C) The Author(s) 2020

\begin{abstract}
To manufacture semi-finished hybrid workpieces with tailored properties, a finite element simulation assisted process chain design was investigated. This includes the process steps of cross wedge rolling, hot geometry inspection, induction hardening, and fatigue testing. The process chain allows the utilisation of material combinations such as high-strength steels with low-cost and easy to process steels. Here, plasma transferred arc welding is applied to supply the process chain with hybrid specimen featuring different steel grades. An overview of the numerical approaches to consider the various physical phenomena in each of the process steps is presented. The properties of the component behaviour were investigated via the finite element method (FEM) and theoretical approaches. At first, the manufacturing of a hybrid workpiece featuring a near net shape geometry with improved mechanical properties due to recrystallising the weld was computed, using the example of a cross wedge rolling process. The rolling process was designed by means of FEM to determine suitable process parameters and to reduce experimental testing. An optical multi-scale geometry inspection of the hot workpiece is meant to be carried out after each manufacturing step to detect potential undesired forming or cooling-induced deformations. Due to the heat transfer from the hot component to the ambient medium, an optical measurement is affected by the developing inhomogeneous refractive index field in air. To gain a basic understanding of the refractive index field and induced light deflection effects, computations were conducted using heat transfer and ray tracing simulations. According to the proposed process route, a subsequent local heat treatment of the hybrid component is required to adapt the mechanical properties by a spray cooling assisted induction hardening. The heat treatment step was computed via a 2D FEM calculation. After finishing by machining, the hybrid material shafts are examined in fatigue tests under load conditions. To predict the component's lifetime under rolling contact fatigue, a damage accumulation model was combined with an FE simulation. The resulting residual stress state after quenching and the geometry after the finishing process were used as input data for the fatigue life calculations.
\end{abstract}

Keywords Process simulation · Tailored forming · Cross wedge rolling · Optical geometry measurement . Induction heating $\cdot$ Bearing fatigue life

\section{Introduction}

Particularly in the transport sector, there is increasing industrial demand for high-performance components, in order to achieve both economic and technical progress [1]. Mechanical components which are made from a

Timm Coors

coors@imkt.uni-hannover.de

Extended author information available on the last page of the article. single material are often limited regarding their mechanical properties in terms of weight, load-bearing capacity, or cost efficiency. A further enhancement in the components' performance can be achieved by combining different materials with properties specially adapted to the respective application. However, common concepts are based on joining components at advanced stages of the process chains, which restricts the modification and improvement of the joining zone properties. By moving the joining process to the very start of the process chain, current research aims to transfer the principle employed for 2dimensional components in the form of sheet metal blanks 


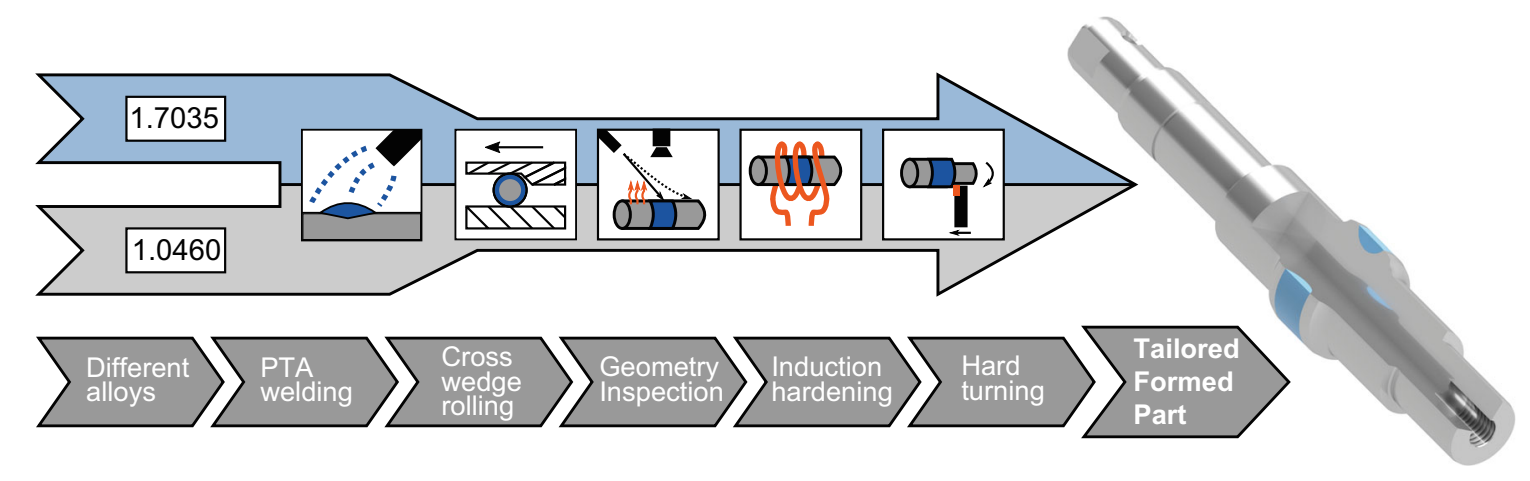

Fig. 1 Exemplary process chain to manufacture hybrid shafts by the technology of Tailored Forming

for the automotive industry (tailored blanks) to complex shaped bulk parts like depicted in Fig. 2 (tailored forming) [1]. An exemplary process route to manufacture hybrid solid components is depicted in Fig. 1. By using semifinished workpieces joined by plasma transferred arc welding (PTA) [2], it is possible to locally adapt the components properties to external loads and additional boundary conditions. A subsequent cross wedge rolling (CWR) process allows a near-net-shape preforming and an improvement of the mechanical properties of the bond due to recrystallisation. The geometrical volume shrinkage of the hot processed components is documented via appropriate optical triangulation sensors, e.g. to characterise the development of material distortion during cooling. The approach is meant to reduce cycle times and energy costs: If the components are instantaneously measured in hot state after forming, the components' temperature can be exploited in subsequent process steps-for instance in heat treatment. The finishing process is carried out by a local inductive hardening and subsequent turning. This allows the manufacturing of highly stressable hybrid solid components which are load-adapted to their specific application.

\section{Research subject}

Machine elements under the influence of rolling contact stresses and structural loads are used in a wide range of industrial applications, e.g. different shafts in powertrains. In order to meet the constantly increasing demand for highly efficient mechanical components, a multi-material shaft, combining a high strength steel (material 1.7035; $41 \mathrm{Cr} 4)$ with an low-cost and well processable base material (material 1.0460; C22.8) was designed and manufactured (see Fig. 2). The higher-grade steel is applied to withstand high radial loading of a cylindrical roller bearing (CRB) without an inner ring, i.e. the $\mathrm{CRB}$ is in direct contact with the hybrid shaft under lubrication.
Due to the rolling contact fatigue resulting from $\mathrm{CRB}$, a steel with a high fatigue limit is required, which, however, usually features poor properties in terms of workability. In order to design the manufacturing of hybrid parts, various simulative approaches were conducted along the presented process chain. Thus, each individual process step is numerically represented in order to understand the material behaviour of mechanical components which are manufactured from hybrid workpieces. Furthermore, the numerical investigations presented below enable the optimisation of production and the prediction of failure under tribological load. The calculations will be validated in further experimental studies. The feasibility of the process chain is meant to be verified by combining numerical and experimental results.

\section{Numerical investigations}

This paper provides an overview of the numerical investigations performed in CRC1153. The focus of this paper is on the individual production steps necessary to numerically

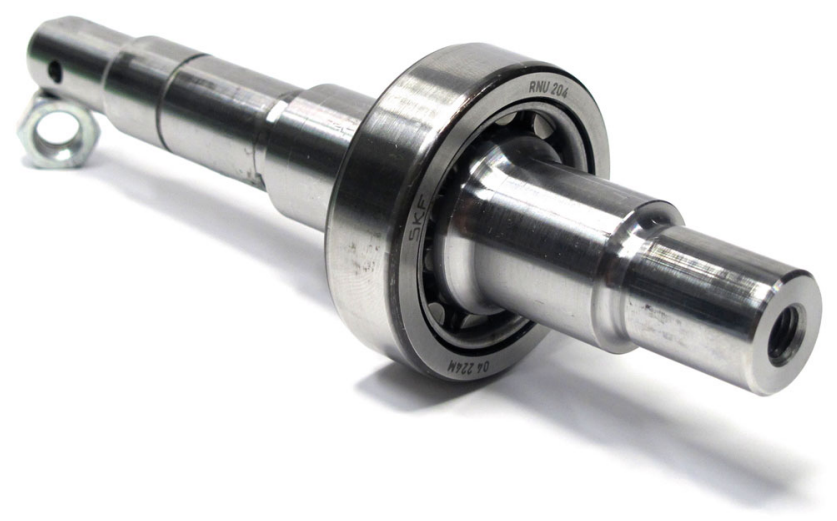

Fig. 2 Hybrid shaft (total length of $146.5 \mathrm{~mm}$ ) with mounted cylindrical roller bearing after testing 
map a complex process chain for multi-material components, to validate them and to create transfer interfaces. Further investigations are presented by the respective authors in separate papers. According to the process chain proposed in Fig. 1, a numerical study of the CWR process is described in Section 3.1 using finite element analysis (FEA). Using FEA, it is possible to represent the forming process of the hybrid semi-finished product numerically. To facilitate an optical inspection of the hot joining zones, the influence of the components' heat on the quality of optical measurements has to be investigated. Due to the heat transfer to the ambient medium, air, an inhomogeneous refractive index field develops around the hot component. Its effect on the light path of a triangulation sensor is analysed in Section 3.2. In the next step, a heat treatment simulation, consisting of inductive heating and a subsequent quenching by spray cooling, is performed (Section 3.3). Based on the simulation results of the aforementioned steps, both the material and heat distribution after the CWR-process can be considered as input data in the simulation. Here, the heat treatment simulation allows the visualisation of the microstructural evolution and the induced residual stresses due to heating and quenching. Subsequently, the residual stresses are used as input data in a mechanical FEA of the finished component after machining under radial load on the CRB (Section 3.4). The resulting stress state in the multi-material components due to rolling contact fatigue (RCF) is used in a statistical damage accumulation model, with which the fatigue life is calculated.

\subsection{Cross-wedge rolling simulation of multi-material parts}

To investigate the cross-wedge rolling (CWR) process of coaxially arranged hybrid parts (Fig. 1), the simulation software Forge NxT 3.0 was used. The forming process is realised by two outer wedge tools in flat tool design and a coaxially arranged hybrid semi-finished workpiece (also referred to as billet; Fig. 3). The workpieces used within the CWR process consist of a cylindrical shaped base material onto which a second material was deposition welded by Subproject (SP) A4 of the CRC 1153 via Plasma transferred arc welding (PTA) within a previous process step (see Fig. 1). The forming of the workpiece takes place due to an opposing movement of the forming tools. The usage of FEA for CWR process design [3, 4] and the simulation model including hybrid material calculation used in this work was validated within previous investigations [5] by comparing simulation and experimental results.

For the computations results shown in this work, the initial workpiece temperature was set to a homogeneous temperature of $1250{ }^{\circ} \mathrm{C}$. The element type of the mesh was chosen to consist of tetrahedral elements. To ensure sufficient accuracy of the calculations, the mesh size was set to $3 \mathrm{~mm}$ for the workpiece. An additional mesh box containing the deposition welded volume and its bounding area to the base cylinder was defined with a constant mesh size of $1 \mathrm{~mm}$. Within the simulation, a hydraulic press with a velocity of $240 \mathrm{~mm} / \mathrm{s}$ was used for the horizontal movement of each CWR tool. The vertical distance of the tools was changed from 33 to $28 \mathrm{~mm}$ in the beginning of the process, resulting in upsetting the billet to, theoretically, remove scale and to adjust the diameter of the part close to the final geometry.

The temperature of the tools was set to an inhomogeneous $180-220{ }^{\circ} \mathrm{C}$ temperature gradient from left to right tool side. To ensure slip-free rolling of the billet between the tools during CWR, the friction preset "tresca-very-high" was used within Forge NxT. The Tresca friction model ( $\tau_{R}=m \cdot k$, where $k$ is the shear yield strength) with $m=0.8$ was used in the FEA simulations, as it is a well-suited approach [3, 5]. The selected thermal exchange condition was set to the predefined "steel-hot-medium", which

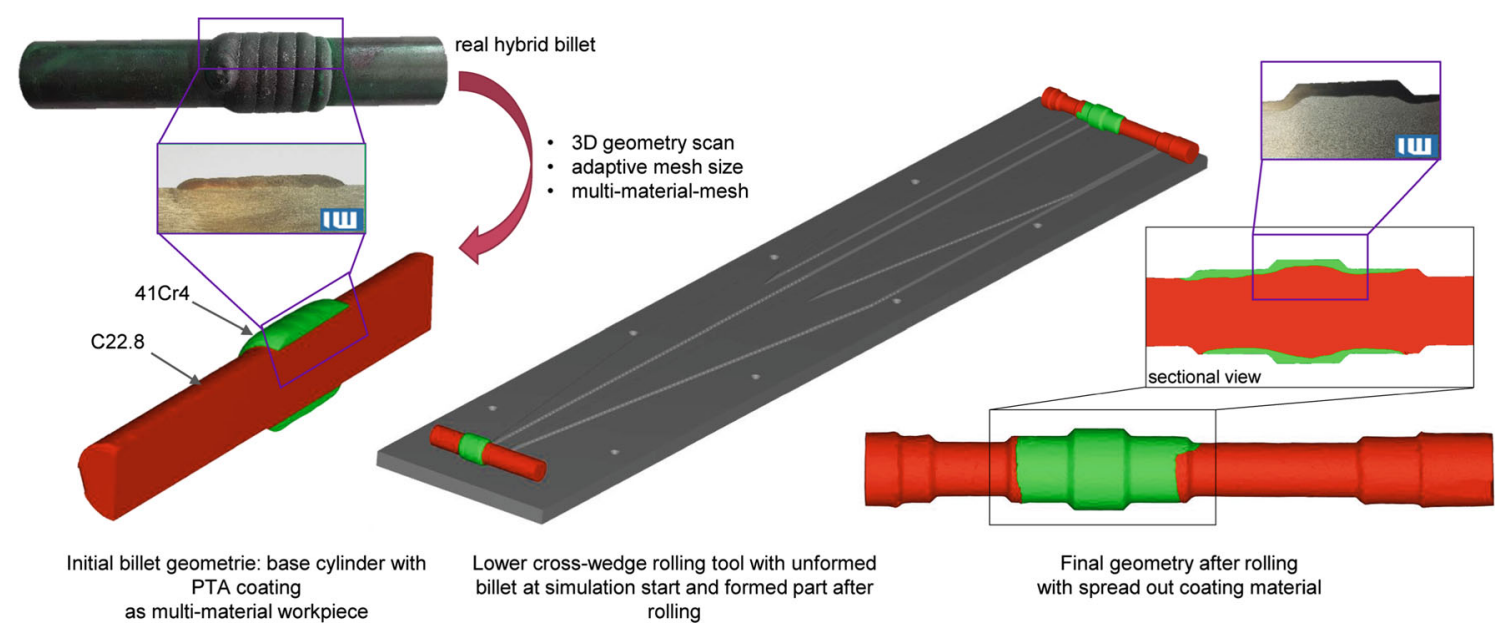

Fig. 3 Simulation setup of the CWR process: initial and end condition coaxially deposition welded billet during CWR 
Table 1 Boundary conditions for cross wedge rolling used in FEA (Forge NxT)

\begin{tabular}{|c|c|c|}
\hline Material & C22.8 (1.0460) & $41 \mathrm{Cr} 4(1.7035)$ \\
\hline Feature & Base cylinder & Deposition welded shaft shoulder \\
\hline Billet dimensions & $\varnothing 28 \mathrm{~mm}$ & $\varnothing 33$ mm \\
\hline Friction factor $m$ & 0.8 & \\
\hline Thermal tool effusivity & $11.76362 \cdot 10^{3} \mathrm{~J} /\left(\mathrm{km}^{2} \mathrm{~s}^{1 / 2}\right)$ & \\
\hline Heat transfer coefficient $\alpha$ & $10 \cdot 10^{3} \mathrm{~W} /\left(\mathrm{m}^{2} \mathrm{~K}\right)$ & \\
\hline
\end{tabular}

contains the thermal tool effusivity and the heat transfer coefficient (see Table 1).

The investigated hybrid-material combination is the base material C22.8 (1.0460) and the high strength steel $41 \mathrm{Cr} 4$ (1.7035). The material description for the hot forming operation can be based on the flow curve equation by Hensel and Spittel [6]. This model describes the forming behaviour of the material in dependence of the temperature $T$, the effective strain, the flow behaviour by parameter $\epsilon$, and the strain rate $\dot{\epsilon}$. Within Forge NxT, the Hensel and Spittelequation is modified (1) [6] as a viscoplastic model. The flow curves and parameters $m_{1-3}$ of some of the used materials within the CRC 1153 are deposited in Forge NxT.

$\sigma_{f}=A \cdot e^{m_{1} T} \cdot \epsilon^{m_{2}} \cdot e^{\frac{m_{4}}{\epsilon}} \cdot \dot{\epsilon}^{m_{3}}$

Especially for the welded on material layer $(41 \mathrm{Cr} 4)$, no exactly matching data is available in Forge, therefore these flow curves were implemented manually into Forge after being measured by $\mathrm{SP} \mathrm{C} 1$ of the CRC 1153. Calculating the FE-model with flow curves taken from the actual material charge used in the experimental investigations enables to minimize deviations.

The initial tool temperature was set to homogenous $T_{d}=250{ }^{\circ} \mathrm{C}$, while the ambient temperature was defined as $T_{a}=50^{\circ} \mathrm{C}$. The modeling of the base cylinder and the welded on layer was realised using the "multi-material"feature within Forge NxT. Initial billet geometry, CWR tools and formed part after simulation are depicted in Fig. 3.

In the top left corner of Fig. 3, the real billet is shown. Below a 3D scan model of the hybrid billet is depicted (base cylinder: blue; deposition welded material: red). The shape of the PTA welded material was optically measured by Subproject C5 of the CRC 1153. Subsequently, the billet is formed between the two tool plates. On the lower right corner of Fig. 3, the simulation result of the formed billet is shown in the bottom right corner. The PTA welded material was spread due to the reduction of the diameter. It was distributed evenly in the area where the bearing is planned to be seated in a future application. It shows, that a little too much $41 \mathrm{Cr} 4$ was coated to the base cylinder. This shows, how the simulation can predict the coating distribution and therefore can be helpful to design the welding process with regard to amount, thickness and position of the coating material. At the outer volumes, no end defect (fishtail) is visible. During the simulation, no unintended forming or slipping occurred. In conclusion, the applied model is suited to simulate the CWR of tailored hybrid parts. Subsequent experiments proved that the simulation results are in good agreement with the experimentally observed forming behaviour, especially within the deposition welded area. The final billet geometry and temperature profile can be exported for further research, i.e. heat treatment simulations after the CWR process. To realise a process monitoring by comparing the shape of the workpiece at the end of the CWR simulation to the geometry after experimental rolling tests, optical triangulation techniques are of interest.

\subsection{Simulation of inhomogeneous refractive index field and induced light deflection}

The measurement accuracy of optical geometry sensors - such as light section or fringe projection sensors [79] — is influenced by the shape and the magnitude of the refractive index field in air. Rays of light emitted by a triangulation sensor's illumination unit are deflected towards more dense air layers (as given by Snell's law [10]), resulting in a deviation from the postulated rectilinear light path. The number of publications related to geometry measurement of high-temperature components is rising, although the temperature-induced light deflection effect is mostly neglected [11, 12]. To investigate this effect, Beermann et al. conducted both simulations and 2D measurements of the inhomogeneous refractive index field above a hot cylinder [13]. An exemplary measurement result of a refractive field above a heated up ceramic rod for different pressure states in air is illustrated in Fig. 4 [14].

To gain a deeper understanding of the deflection effects, a 3D FEM model was developed using the software COMSOL Multiphysics and the associated heat transfer and ray tracing modules.

In a first heat transfer simulation step, a simple 3D monomaterial steel cylinder is hypothesised to reduce calculation costs. The cylinder dimensions are diameter $d=27 \mathrm{~mm}$ and length $l=170 \mathrm{~mm}$. The steel cylinder incorporates an initial temperature of $900{ }^{\circ} \mathrm{C}$ to represent a slightly cooled down workpiece after forming. The ambient air has an initial temperature of $20{ }^{\circ} \mathrm{C}$. An isobaric process 


$$
\mathrm{p}_{1}=987 \mathrm{mbar} \quad \mathrm{p}_{2}=332 \ldots 345 \mathrm{mbar}
$$
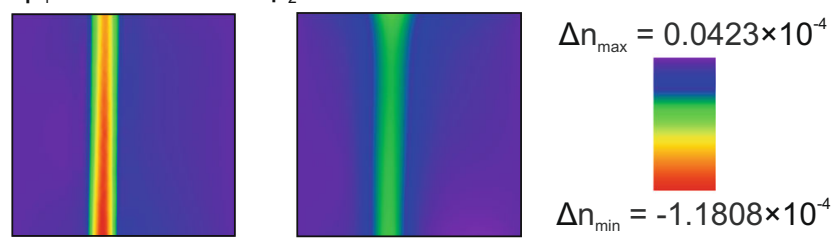

$\left|\Delta \mathrm{n}_{1}\right|=1.1907 \times 10^{-4} \quad\left|\Delta \mathrm{n}_{2}\right|=0.4746 \times 10^{-4}$

Fig. $42 \mathrm{D}$ measurement of inhomogeneous refractive index field variation $n-n_{0}=\Delta n$ directly above ceramic heating rod (diameter $d=11 \mathrm{~mm}$, temperature $T \approx 1000{ }^{\circ} \mathrm{C}$ ) for air at different pressure states. The camera's field of view is approximately $80 \mathrm{~mm}$ by $80 \mathrm{~mm}$. The absolute variation $|\Delta n|$ is reduced, if the air pressure is lowered

is postulated. Furthermore, only laminar heat flow is permitted. A 3D density field is obtained via heat transfer simulation $(t=15 \mathrm{~s})$, assuming natural convection. The density data is directly evaluated by extrapolating Ciddor's equation [15], resulting in a 3D inhomogeneous refractive index field. Cross sections of the field are depicted in Fig. 5. Due to the convective heat flow, the greatest spatial field extension is located above the cylinder-this is in accordance with the measurement in Fig. 4.

These regions are exemplarily analysed in terms of light deflection, when measuring the hot component from above. For this purpose, a point laser is hypothesised as illumination unit, emitting green light. The ray tracing algorithms are based on the principles of wave optics, approximating the electromagnetic field locally by plane waves. The rays' phase is hypothesised to be linearly dependent on time and position. For detailed information refer to the COMSOL software guide and, e.g., Refs. [16, 17]. A laser line with a width of $6 \mathrm{~mm}$ is approximated by

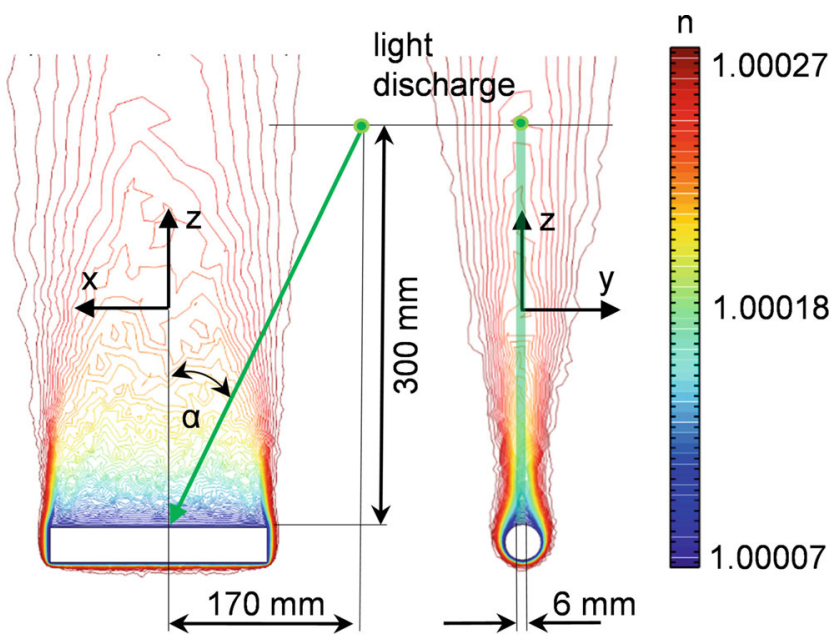

Fig. 5 Cross sections of inhomogeneous refractive index field around hot steel cylinder after a heat transfer simulation time of $t=15 \mathrm{~s}$. The rectilinear light path under homogeneous conditions is indicated in green seven discrete light rays only differing in the $y$-discharge location, given as $(-3,-2,-1,0,+1,+2,+3) \mathrm{mm}$. A potential triangulation angle could be $\alpha=30^{\circ}$, provided the camera is directly located above the cylinder. The laser light spot position on the cylinder surface is simulated with and without the influence of the inhomogeneous refractive index field in air. The simulation results for both scenarios are compared to quantify the amount of light deflection induced spot shift. The results are displayed in Fig. 6, revealing an approximately symmetrical spot displacement profile (Euclidean norm). Deviations from a perfect symmetry are potentially due to numerical rounding and meshing effects of the refractive field and the cylinder's surface geometry. Depending on the sensor resolution, displacement values of comparable magnitude as given in Fig. 6 can already negatively affect the quality of an actual optical measurement. To allow for a full characterisation of accuracy loss, the simulation model was extended by a virtual camera as detection unit to model a complete triangulation sensor [18]. The comprehension of light deflection effects is exploited to design an appropriate triangulation sensor for the geometry acquisition of, e.g., CRW workpieces directly after forming.

\subsection{Heat treatment simulation}

Following the process chain, the shaft has been cross wedge rolled and has been cooled. The shaft then is surface hardened by employing induction heating and a subsequent quenching by air-water spray cooling. The heat treatment process is modelled in the FEM software

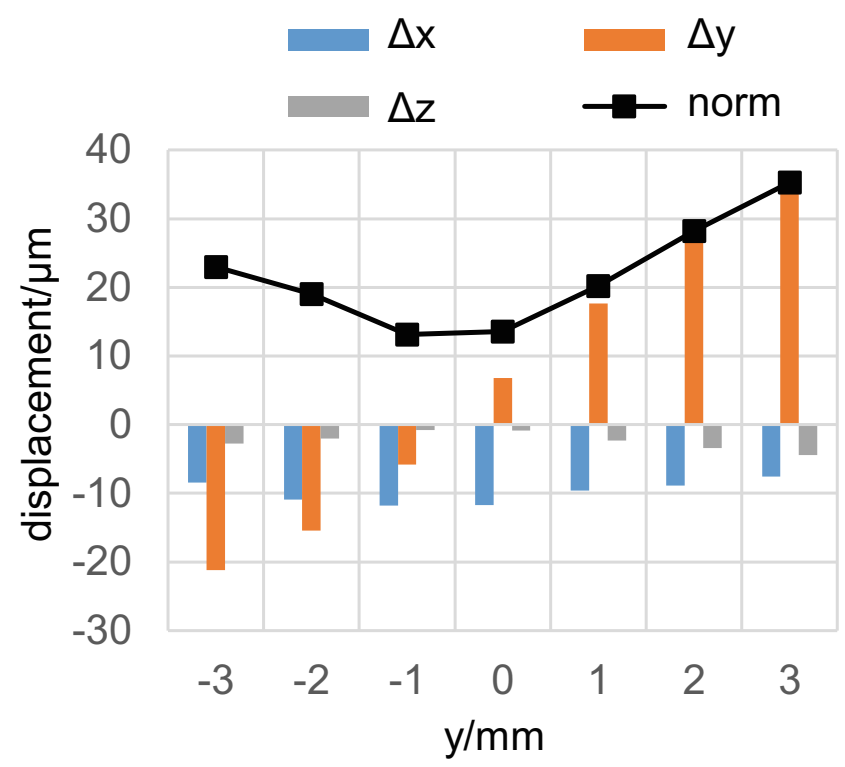

Fig. 6 Light spot displacement for seven different locations on cylinder surface induced by inhomogeneous refractive index field 
DEFORM-2D, utilising the rotational symmetry of the setup. This software offers modules for induction heating, heat transfer (e.g. for quenching) and phase transformations with correlated hardness calculations. From the final simulation step of the cross-wedge rolling, the mesh data of the shaft was transformed to a rotational symmetric 2D model, defining the geometry and material distribution. Figure $7 \mathrm{a}$ depicts the meshed model.Thermo-physical and transformation material data was imported from JMatPro for the five microstructural constituents austenite, ferrite, pearlite, bainite, and martensite. The deformation behaviour was implemented via measured flow curves (cf. Section 3.1) and the electromagnetic properties were adapted from [19]. Regarding the interface between the materials C22.8 and $41 \mathrm{Cr} 4$ in the shaft, the contact condition was chosen to be sticking with an infinite heat transfer coefficient to account for the deposition welded and CWR formed material transition.

The heating was modelled by defining a constant electrical input power at the induction coil of $90 \mathrm{~kW}$ with a frequency of $115 \mathrm{kHz}$ in the induction heating module of the FEM software and an electrical to thermal power conversion ratio of $60 \%$. By employing 500 simulation steps, a heating time of $0.5 \mathrm{~s}$ was simulated. Subsequently, the quenching by air water spray cooling was simulated for $10 \mathrm{~s}$ (additional 1000 simulation steps) by employing experimentally determined heat transfer coefficients (cf. [20]) on the cylindrical surface in the axial centre of the shaft. After $0.5 \mathrm{~s}$ of heating, a maximum temperature of $1270{ }^{\circ} \mathrm{C}$ is calculated, which is in good accordance to the maximum temperature measured by means of thermography $\left(1257^{\circ} \mathrm{C}\right)$. During quenching, the maximum temperature in the shaft is reduced to $110{ }^{\circ} \mathrm{C}$. The volume fraction of martensite after this quenching operation is depicted in Fig. 7b). The depth, to which martensite is formed is about $1.8 \mathrm{~mm}$, which correlates well with micrographs of hybrid shafts experimentally hardened with the same process parameters like in the calculations (see Fig. 7b, $\mathrm{d}$, e). Due to the increase in specific volume during the transformation from austenite to martensite, high residual compressive stresses up to $640 \mathrm{MPa}$ in circumferential (cf. Fig. 7c) and axial direction develop in the hardened area. Hence, to reach a state of equilibrium, high residual tensile stresses in the surrounding areas are induced, especially in the vicinity of the bond zone. The calculated residual stresses are transferred to the numerical simulation of the next process to compute the resulting fatigue life.

\subsection{Bearing fatigue life model for the hybrid part zone}

Under operating conditions, the finished hybrid shaft is exposed to RCF due to the CRB contact, which leads to unavoidable material fatigue [21]. Under full film lubrication, this is the limiting failure mechanism for this application. According to ISO 281 [22] the fatigue life of a rolling element bearing can be calculated based on the extendet fatigue life model proposed by Ioannides and Harris [24, 25], which provides the probability of survival $S$ for a volume in damage risk $V$ in dependence of the number of load cycles $N$ :

$\ln \left(\frac{1}{S}\right) \approx N^{e} \int_{V} \frac{\left(\tau_{i}-\tau_{u}\right)^{c}}{z^{\prime h}} \mathrm{~d} V$

This approach is based on the model of Lundberg and Palmgren [26] by including a stress fatigue limit $\tau_{u}$
Fig. 7 a Meshed model. b Calculated volume fraction of martensite with an overlayed micrograph cutout. c Calculated stresses in circumferential direction after quenching. $\mathbf{d}$ Micrograph of experimentally hardened area. e Detail of $\mathbf{d}$ confirming a martensitic microstructure at the hardened surface a)

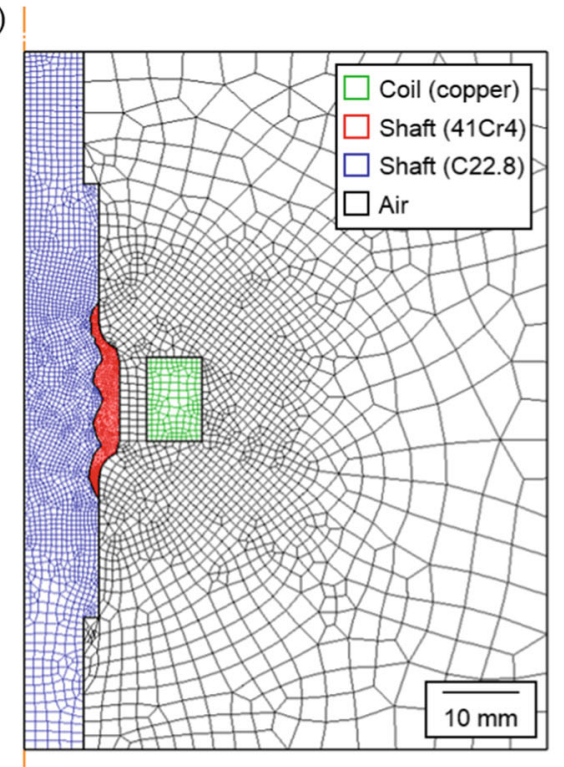

b)

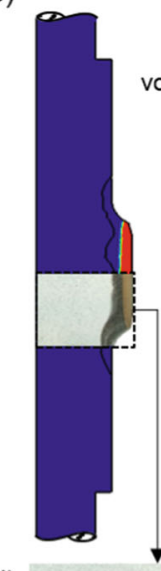

d)

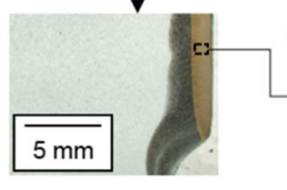

c)

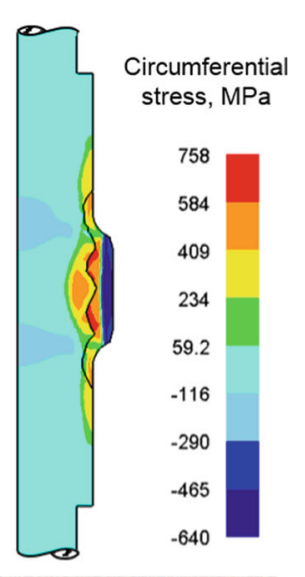

e)

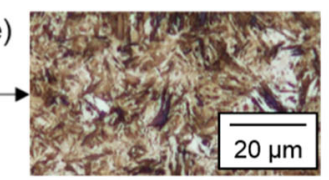


(material constant). For the term $\tau_{i}$ the fatigue stress criterion of Dang Van [27] was selected. The parameter $z^{\prime}$ represents a stress weighted depth from the surface; $e$, $c$ and $h$ are constant exponents. Although the use of a fatigue limit $\tau_{u}$ is discussed [23, 28], the above approach is still frequently used and is being extended [29, 30]. An FE-model of a bearing raceway was set up in ANSYS APDL to compute the resulting three-dimensional stress field from the superimposition of load stresses and residual stresses, which are necessary for the subsequent fatigue life calculation. In order to reduce the required computing time for this static-elastic FEA, the symmetry of geometry and periodic boundary conditions are taken into account. The contact region was discretised by eight-node elements type SOLID185 as mapped mesh. This element replaces volumetric strains at the Gaussian integration points by an average volumetric strain of the elements (selective reduced integration method). The remaining volumes were free meshed with tetrahedral element geometry. The load is applied to the inner ring as a three-dimensional pressure distribution, which was previously calculated for a Hertzian contact between rolling element and inner ring. As coefficient of friction, $\lambda=0.0015$ was assumed for fully flooded conditions. Cylindrical rollers with a diameter of $6.5 \mathrm{~mm}$ are utilised as of CRB type RNU204. Other input variables are the local material properties of the hybrid component, the geometry of the joining zone after the CWR simulation (cf. Section 3.1), and the rolling element crowning and profile. The resulting residual stress depth profiles from the heat treatment simulation (cf. Section 3.3) or after machining can be imposed as initial stress. The

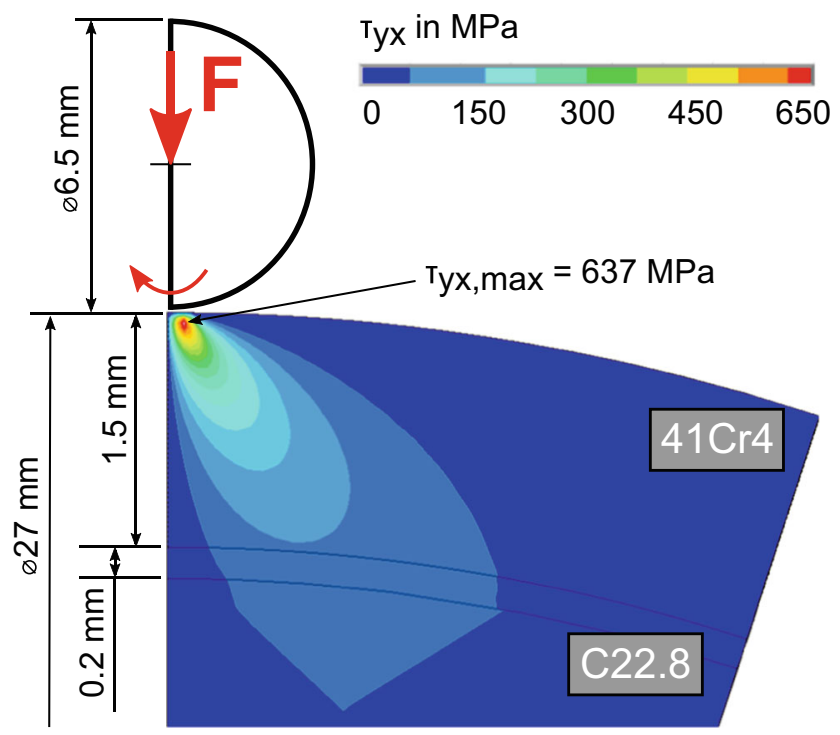

Fig. 8 Resulting orthogonal shear stress in $x$-y-plane $\tau_{y x}$ from a radial bearing load of $5880 \mathrm{~N}$ (Hertzian contact pressure $p_{\max }=1870 \mathrm{MPa}$, $C / P=7$ equivalent) simulation results in Fig. 8 show the orthogonal shear stress in the vertical sectional plane at one half of the bearing width, which is an input for Eq. 2. For a layer thickness of $1 \mathrm{~mm}$, the maximum of orthogonal shear stress is located at a depth of $0.15 \mathrm{~mm}$ beneath the surface, where fatigue failure occurs through crack formation. A reduction of the thickness of the top layer leads to an increase of the stress maximum. The base material is also exposed to a higher amount of stress, which is why a thin and cheap coating would not be sufficiently dimensioned for the considered load parameters. The equivalent stress in the depth of the base material (1.5 mm below the surface) however, is low enough to apply common structural steel. Figure 9 shows the probability of survival of the hybrid shaft, based on the fatigue life model proposed by Ioannides and Harris (see Eq. 2) in combination with the Dang Van fatigue criterion. This calculation was compared with experimentally determined failure rates of $10 \%, 50 \%$ and $63,5 \%$ probability, from [31]. An exemplary damage caused by RCF on the raceway of the hybrid shaft is also shown in this figure, which was acquired by confocal laser scanning microscopy. A maximum damage depth of $147.4 \mu \mathrm{m}$ could be measured, which corresponds approximately to the depth of the maximum shear stress amplitude according to the simulation.

The current residual stress state does not seem to have a significant influence on the fatigue life prediction because the specific depth profile and the maximum value are low. However, previous investigations have shown that

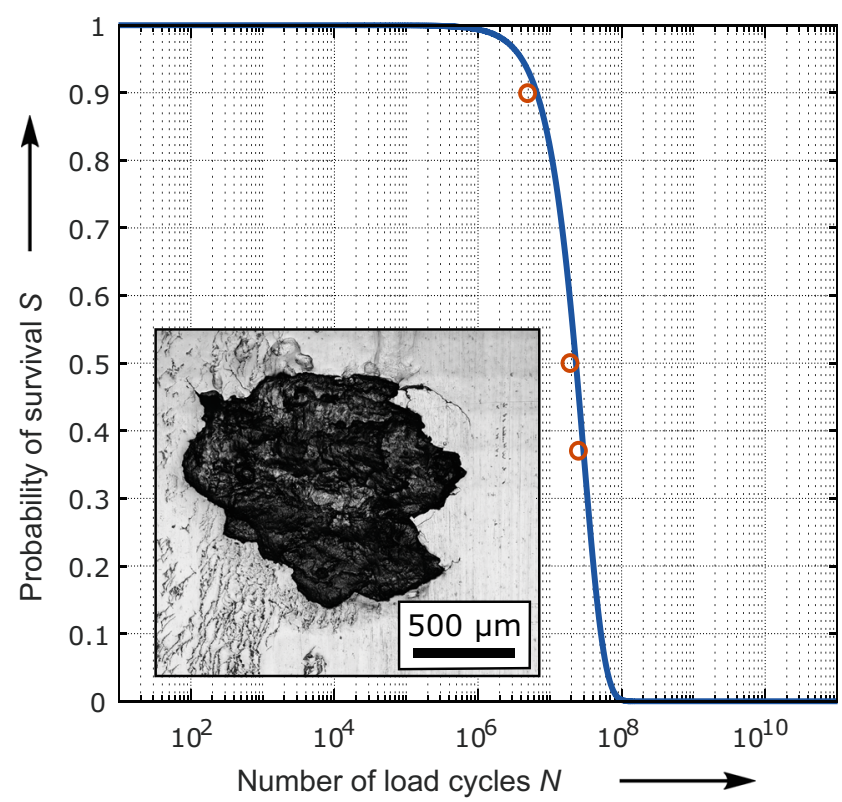

Fig. 9 Calculated fatigue life of the multi-material shaft (blue line) with experimental data from monolithic specimen for $10 \%, 50 \%$ and $63,5 \%$ likelihood of failure (red dots) and exemplary damage on the hybrid shafts' raceway 
a considerable increase in fatigue life can be achieved through adapted manufacturing processes and targeted insertion of residual stresses [31]. A further process chain optimisation-accompanied by numerical investigationsis therefore of major interest. The theoretical considerations have been verified by experimental studies with physical tests at the example of specimen made from monolithic $41 \mathrm{Cr} 4$ shafts, which showed a good agreement with the fatigue life prediction. These findings will be extended through experimental studies on different test benches and with hybrid specimen with different geometries during the further progress of the project. The presented approach can be transferred to further machine elements, like washers for axial cylindrical roller bearings [32].

\section{Conclusion}

Within the scope of this study, a simulation approach has been developed to compute the subsequent steps of a multistep process chain for the manufacturing of load-adapted Tailored Forming components. Based on the results, the following conclusions can be drawn:

- The CWR process is adaptable for mechanical components made from different metallic materials. The process can be designed with the aid of numerical investigations.

- When optically measuring hot Tailored Forming components, the light deflection due to inhomogeneous refractive index fields in air cannot be neglected. A simulation of the refractive index field and its impact on optical measurements are meant to be consulted to design an appropriate sensor concept. This approach is meant to enable high precision measurements of distortion and shrinkage and contributes to high level process reliability and near net-shape production.

- Local heat treatment of hybrid components can be designed using FEA, based on input data from the CWR process. Thus, components can be adapted to high mechanical loads by means of improved hardness values and residual stresses. The measured martensite distribution and volume fractions agree well with the calculated values. The calculated residual stress state can be used for subsequent fatigue life calculations.

- The possibility to predict complex dynamic stress states in mechanical components, considering the comprehensive manufacturing history, is of major interest to establish new process chains. The combination of theoretical approaches and experiments allows for an applicationoriented dimensioning of hybrid components.

By combining theoretical and numerical investigations, it could be demonstrated that the developed process chain provides substantial opportunities to enhance components by locally adapting their mechanical properties.

Acknowledgements The authors thank the German Research Foundation (DFG) for the financial and organisational support of this project.

Funding information Open Access funding provided by Projekt DEAL. The results presented in this paper were obtained within the Collaborative Research Centre 1153 "Process chain to produce hybrid high performance components by Tailored Forming" in the subprojects A2, B1, C3 and C5 (grant number 252662854).

Open Access This article is licensed under a Creative Commons Attribution 4.0 International License, which permits use, sharing, adaptation, distribution and reproduction in any medium or format, as long as you give appropriate credit to the original author(s) and the source, provide a link to the Creative Commons licence, and indicate if changes were made. The images or other third party material in this article are included in the article's Creative Commons licence, unless indicated otherwise in a credit line to the material. If material is not included in the article's Creative Commons licence and your intended use is not permitted by statutory regulation or exceeds the permitted use, you will need to obtain permission directly from the copyright holder. To view a copy of this licence, visit http:// creativecommonshorg/licenses/by/4.0/.

\section{References}

1. Enomoto Y, Yamamoto T (1998) New materials in automotive tribology. Tribol Lett 5(1):13-24. https://doi.org/10.1023/A:1019100531912

2. Blohm T, Mildebrath M, Stonis M et al (2017) Investigation of the coating thickness of plasma-transferred arc deposition welded and cross wedge rolled hybrid parts. Product Eng Res Develop 11:255-263. https://doi.org/10.1007/s11740-017-0734-7

3. Pater Z (2014) Cross-wedge rolling. In: Button ST (ed) Comprehensive materials processing, vol 3. Elsevier Ltd, pp 211279

4. Pater Z, Tomczak J, Bulzak T (2018) New forming possibilities in cross wedge rolling processes. Arch Civil Mech Eng 18(1):149161. https://doi.org/10.1016/j.acme.2017.06.005

5. Kruse J, Jagodzinski A, Langner J et al (2019) Investigation of the joining zone displacement of cross-wedge rolled serially arranged hybrid parts. Int J Mater Form. https://doi.org/10.1007/s12289-019-01494-3

6. Hensel A, Spittel T (1978) Kraft- und Arbeitsbedarf bildsamer Formgebungsverfahren. Verlag Grundstoffindustrie

7. Gorthi SS, Rastogi P (2010) Fringe projection techniques: Whither we are? Opt Lasers Eng 48(2):133-140. https://doi.org/10.1016/j.optlaseng.2009.09.001

8. Van der Jeught S, Dirckx JJJ (2016) Real-time structured light profilometry: a review. Opt Lasers Eng 87:18-31. https://doi.org/10.1016/j.optlaseng.2016.01.011

9. Abu-Nabah BA, ElSoussi AO, Al Alami AEK (2016) Simple laser vision sensor calibration for surface profiling applications. Opt Lasers Eng 84:51-61. https://doi.org/10.1016/j.optlaseng.2016.03.024

10. Kidger MJ (2001) Fundamental optical design. Bellingham, SPIE. ISBN: 0-8194-3915-0

11. Liu W, Jia X, Jia Z et al (2011) Fast dimensional measurement method and experiment of the forgings under 
high temperature. J Mater Process Technol 211(2):237-244. https://doi.org/10.1016/j.jmatprotec.2010.09.015

12. Ghiotti A, Schöch A, Salvadori A et al (2015) Enhancing the accuracy of high-speed laser triangulation measurement of freeform parts at elevated temperature. CIRP Ann 64(1):499-502. https://doi.org/10.1016/j.cirp.2015.04.012

13. Beermann R, Quentin L, Pösch A et al (2017) Background oriented schlieren measurement of the refractive index field of air induced by a hot, cylindrical measurement object. Appl Opt 56(14):4168-4179. https://doi.org/10.1364/AO.56.004168

14. Beermann R, Quentin L, Reithmeier E, Kästner $M$ (2018) 2D refractive index field measurements in air in different pressure scenarios. Proc SPIE 10819:53-60. https://doi.org/10.1117/12.2500315

15. Ciddor PE (1996) Refractive index of air: new equations for the visible and near infrared. Appl Opt 35(9):1566-1573. https://doi.org/10.1364/AO.35.001566

16. Born M et al (1999) Principles of optics: electromagnetic theory of propagation in: interference and diffraction of light, 7th edn. Cambridge University Press, Cambridge

17. Krueger DA (1980) Spatial varying index of refraction: an open ended undergraduate topic. Am J Phys 48:183-188. https://doi.org/10.1119/1.12169

18. Beermann R, Quentin L, Stein G et al (2018) Full simulation model for laser triangulation measurement in an inhomogeneous refractive index field. Opt Eng 57(11):114107-1-114107-13. https://doi.org/10.1117/1.OE.57.11.114107

19. Nacke B (1987) Ein Verfahren zur numerischen Simulation induktiver Erwärmungsprozesse und dessen technische Anwendung. Dissertation, University Hannover

20. Herbst S, Steinke KF, Maier HJ et al (2016) Determination of heat transfer coefficients for complex spray cooling arrangements. Int J Microstruct Mater Prop 11:229-246. https://doi.org/10.1504/IJMMP.2016.079149

21. Harris TA, Kotzalas MN (2006) Rolling bearing analysis, 5th edn. CRC Press
22. 281 ISO (2007) Rolling bearings-dynamic load ratings and rating life. International Organization for Standardization, Geneva

23. Zaretsky EV, Poplawski JV, Peters SM (1996) Comparison of life theories for rolling-element bearings. Tribol Trans 39(2):237-248. https://doi.org/10.1080/10402009608983525

24. Ioannides E, Harris $\mathrm{T}$ (1985) A new fatigue life model for rolling bearings. J Tribol 107(3):367-378. https://doi.org/10.1115/1.3261081

25. Ioannides E, Berling G, Gabelli A (1999) An analytical formulation for the life of rolling bearings Mech Eng Ser 137. Espoo, Acta Polytechnica Scandinavica

26. Lundberg G, Palmgren A (1952) Dynamic capacity of roller bearings. Mech Eng Ser. Royal Swedish Academy of Engineering Sciences, Stockholm

27. Dang Van K (1973) Sur la résistance à la fatigue des métaux Sciences Techniques Armement 47. Imprimerie Nationale, Paris

28. Zaretsky EV, Poplawski JV (1996) Discussion: on the accuracy of rolling bearing fatigue life prediction (Harris TA, McCool JI (1996), ASME J Tribol 118(2):297-309). ASME J Tribol 118(2):309-310. https://doi.org/10.1115/1.2831300

29. El Laithy M, Wang L, Harvey TJ et al (2019) Further understanding of rolling contact fatigue in rolling element bearings - a review. Tribol Int 140:105849. https://doi.org/10.1016/j.triboint.2019.105849

30. Gabelli A, Morales-Espejel GE (2019) A model for hybrid bearing life with surface and subsurface survival. Wear 422-423:223-234. https://doi.org/10.1016/j.wear.2019.01.050

31. Coors T, Pape F, Poll G (2018) Bearing fatigue life of a multimaterial shaft with an integrated raceway. Bearing World J 3:23-30. PDF-ISSN: 2566-4794

32. Behrens BA, Chugreev A, Matthias T (2019) Manufacturing and evaluation of multi-material axial-bearing washers by tailored forming. Metals 9(2):232. https://doi.org/10.3390/met9020232

Publisher's note Springer Nature remains neutral with regard to jurisdictional claims in published maps and institutional affiliations.

\section{Affiliations}

Timm Coors ${ }^{1}$ (D) . Florian Pape ${ }^{1} \cdot$ Jens Kruse $^{2}$ - Thoms Blohm² - Rüdiger Beermann ${ }^{3}$ - Lorenz Quentin ${ }^{3}$. Sebastian Herbst ${ }^{4} \cdot$ Jan Langner $^{2} \cdot$ Malte Stonis $^{2} \cdot$ Markus Kästner $^{3} \cdot$ Eduard Reithmeier $^{3} \cdot$ Florian Nürnberger $^{4} \cdot$ Gerhard Poll $^{1}$

1 Institut für Maschinenkonstruktion und Tribologie (Machine Design and Tribology), Leibniz University Hannover, Hannover, Germany

2 Institut für Integrierte Produktion Hannover gGmbH, Hannover, Germany

3 Institut für Mess- und Regelungstechnik (Measurement and Automatic Control), Leibniz University Hannover, Hannover, Germany

4 Institut für Werkstoffkunde (Material Science), Leibniz University Hannover, Hannover, Germany 